\section{Medium-incorporated PEG-8000 Reduces Elongation, Growth, and Whole-canopy Carbon Dioxide Exchange of Marigold}

\author{
Stephanie E. Burnett ${ }^{1}$ \\ Department of Plant, Soil, and Environmental Sciences, University of Maine, \\ 5722 Deering Hall, Orono, ME, 04469
}

Marc W. van Iersel and Paul A. Thomas

Department of Horticulture, University of Georgia, 1111 Miller Hall Plant Sciences Building, Athens, GA, 30602

Additional index words. marigold, drought, photosynthesis, respiration, seedling

\begin{abstract}
French marigold (Tagetes patula L. 'Boy Orange') was grown in a peat-based growing medium containing different rates $\left(0,15,20,30,42\right.$, or $\left.50 \mathrm{~g} \cdot \mathrm{L}^{-1}\right)$ of polyethylene glycol 8000 (PEG-8000) to determine if PEG-8000 would reduce seedling height. Only $28 \%$ to $55 \%$ of seedlings treated with 62,72 , or $83 \mathrm{~g} \cdot \mathrm{L}^{-1}$ of PEG-8000 survived, and these treatments would be commercially unacceptable. Marigolds treated with the remaining concentrations of PEG-8000 had shorter hypocotyls, and were up to $38 \%$ shorter than nontreated controls at harvest. Marigold cotyledon water $\left(\Psi_{w}\right)$, osmotic $\left(\Psi_{\mathrm{s}}\right)$, and turgor $\left(\Psi_{p}\right)$ potentials were significantly reduced by PEG-8000, and $\Psi_{\mathrm{p}}$ was close to zero for all PEG-treated seedlings 18 days after seeding. Whole-plant net photosynthesis, whole-plant dark respiration, and net photosynthesis/leaf area ratios were reduced by PEG-8000, while specific respiration of seedlings treated with PEG-8000 increased. Marigolds treated with concentrations greater than $30 \mathrm{~g} \cdot \mathrm{L}^{-1}$ of PEG-8000 had net photosynthesis rates that were close to zero. Fourteen days after transplanting, PEG-treated marigolds were still shorter than nontreated seedlings and they flowered up to 5 days later. Concentrations of PEG from 15 to $30 \mathrm{~g} \cdot \mathrm{L}^{-1}$ reduced elongation of marigold seedlings without negatively affecting germination, survival, or plant quality. It appears that marigold seedlings were shorter because of reduced leaf $\Psi_{\mathrm{p}}$ and reductions in net photosynthesis.
\end{abstract}

French marigold is a classic landscape bedding plant that flowers throughout the entire summer (Armitage, 2001). However, marigolds grow rapidly and stretch when grown in greenhouses. Seedling transplants, especially, out-grow their small substrate volumes quickly and become leggy (Styer and Koranski, 1997). Overgrown transplants are difficult to grow and more expensive to ship than shorter transplants. This is a serious problem for seedling producers who sell their products to other growers. Purchasers of seedlings have higher expectations of plant quality than the average consumer.

A particular problem for marigold seedling growers is that most marigold seedling elongation is in the hypocotyl, which may account for $60 \%$ of overall seedling height (Burnett, 2004). So, to successfully control height of marigolds, one must reduce hypocotyl height. Low levels of drought stress result in physiological ef-

Received for publication 19 Aug. 2005. Accepted for publication 27 Oct. 2005. Based on part of a dissertation in partial fulfillment of the requirements for a $\mathrm{PhD}$ degree at the University of Georgia. Maine Agriculture and Forestry Experiment Station Publ. 2832. We thank Carrie Radcliffe and Matt Hawkins for technical assistance and Bodie Pennisi, Hugh Earl, Peter Hartel, and Hazel Wetzstein for their helpful comments on an early draft of this manuscript.

${ }^{1}$ To whom reprint requests should be addressed; e-mail sburnett-maine.edu. tion without risking plant damage or death. One option is to use osmotic compounds, such as polyethylene glycol-8000 (PEG-8000), to reduce plant growth. Polyethylene glycol is an inert molecule that readily bonds with water (Kjellander and Florin, 1981). PEG-8000 reduces $\Psi_{w}$ when added to water (Michel, 1983). Researchers have used PEG of varying molecular weights to study the effects of osmotic stress on plants as early as 1961 (Lagerwerff et al., 1961). Recently, we evaluated the possibility of using PEG to reduce elongation of marigold seedlings. When PEG-8000 solutions (15 to $50 \mathrm{mg} \cdot \mathrm{L}^{-1}$ ) were added to a peat-based growing medium after germination as drenches, PEG reduced marigold seedling growth and hypocotyl elongation (Burnett et al., 2005). Low rates of PEG-8000 did not appear to damage plants (Burnett et al., 2005). Continuous, low-level drought stress, where plants are not allowed to visibly wilt, would be more practical in commercial settings than episodic drought (Liptay et al., 1998). PEG is not currently labeled as a growth retardant for greenhouse use, and the cost is prohibitive for commercial growers $(\$ 0.009$ for one seedling in an $8.5-\mathrm{mL}$ cell). However, if commercial greenhouse growers are interested in the use of PEG or other osmotic compounds, these obstacles may be overcome.

Since one of the negative effects of drought is decreased photosynthesis, we were interested in determining what PEG concentrations may limit whole plant photosynthesis. Annual salvia exposed to episodic drought, where plants are drought-stressed to the wilting point (with leaves reaching $\Psi_{w}$ of -1.1 to $-1.4 \mathrm{MPa}$ on four separate occasions) photosynthesize less than nonstressed plants (Eakes et al., 1991). Since plant production is driven by photosynthesis (Loomis and Amthor, 1999), drought-induced reductions in photosynthesis will decrease growth. Therefore, the primary purpose of this experiment was to determine which PEG- 8000 concentrations reduce elongation of marigold seedlings without damaging plants. Secondly, we determined whether PEG- 8000 reduces whole-plant photosynthesis and respiration and leaf water potential of marigolds.

\section{Materials and Methods}

Polyethylene glycol 8000 was mixed with water and added to a peat-based growing medium specifically formulated for germinating seedlings (a mixture of sphagnum peat, perlite, and vermiculite; germinating mix; Fafard, Anderson, S.C.) to obtain the following concentrations in the growing medium: 0 , $15,20,30,42,50,62,70$, and $83 \mathrm{~g} \cdot \mathrm{L}^{-1}$. Each PEG-8000 and growing medium combination was then shaken vigorously in a large plastic container for ten minutes to produce a homogenous mix. Substrate $\Psi_{w}$ of three samples from each treatment was measured using a vapor pressure osmometer (model 5520 Vapro vaporpressure osmometer; Wescor, Logan, Utah). The volumetric water content of the growing medium during these measurements was about $29.3 \%$, which was the target water content for the duration of the experiment. Experimental 
units were $6 \times 6$-cell sections cut from trays with 288 cells (cell volume $=8.5 \mathrm{~mL}$ ). Empty trays were weighed for calculation of water contents (described later), and then treated growing medium was placed in each tray.

Two marigold 'Boy Orange' (Pan American Seed Co., West Chicago, Ill.) seeds were planted in each cell on 6 June 2003. Marigold seeds were germinated in a growth chamber (E-15; Conviron, Winnipeg, Man., Canada) (temperature $=20{ }^{\circ} \mathrm{C}$ ). While in the growth chamber, plants were misted overhead by hand as needed to maintain a constant volumetric water content $(29 \% \pm 3 \%)$. After emergence (cotyledons were perpendicular to the hypocotyl, $11 \mathrm{~d}$ after seeding), seedlings were grown on a mist bench in a glasshouse (temperature $=$ $24.6 \pm 4.2^{\circ} \mathrm{C}$ ) and irrigated about 20 s every 30 min from 8:00 AM to 5:00 PM (EST). Irrigation was adjusted later in the experiment to maintain similar volumetric water contents and minimize leaching. Mist irrigation was changed to $20 \mathrm{~s}$ every $20 \mathrm{~min}$ from 6:00 AM until 6:00 PM $15 \mathrm{~d}$ after seeding, then changed again to $20 \mathrm{~s}$ every $30 \mathrm{~min}$ from 6:00 AM until 6:00 PM $19 \mathrm{~d}$ after seeding.

Experimental unit weight was recorded twice daily for the duration of the experiment and plants were removed from mist when necessary to maintain constant volumetric water contents. This also prevented leaching which would result in loss of PEG and thus change treatment levels. At this point, one seedling from the outermost row was harvested biweekly. The weight of this seedling was multiplied by the number of plants in each tray to account for changes in plant weight throughout the experiment. Each tray contained about 307 $\mathrm{mL}$ of growing medium, and the same volume of excess treated growing medium was dried in an oven at about $80^{\circ} \mathrm{C}$. So, the amount of water in each tray was calculated by subtracting the tray, seedling, and dry growing medium weight from the experimental unit weight. The drying oven did not completely remove all the water bonded to PEG-8000 from the growing medium (unpublished results). Thus, the estimated dry weight of the PEG-treated growing media included some water, which apparently was hygroscopically bound to the PEG-8000. This water was not available for plant uptake.

The smaller seedling was removed from cells containing more than one plant at $22 \mathrm{~d}$ after seeding. All seedlings were fertilized twice weekly with a $20 \mathrm{~N}-8.7 \mathrm{P}-16.6 \mathrm{~K}$ fertilizer (20-20-20 General Purpose, Scotts Company, Marysville, Ohio) solution with a N-concentration of $200 \mathrm{mg} \cdot \mathrm{L}^{-1}$, beginning when the first true leaves were visible ( $23 \mathrm{~d}$ after seeding). When seedlings were fertilized, they were removed from the mist bench and hand-misted overhead with a fertilizer solution using a mist nozzle for $20 \mathrm{~s}$.

Data collected include the number of days to seedling emergence and percentage emergence [the number of emerged (dead and live) seedlings $\times 100 \%, 22 \mathrm{~d}$ after seeding]. Plants in the outside rows of the $6 \times 6$-cell sections were not used for these measurements to prevent edge effects. After plants were moved to the greenhouse, the emergence and survival percentages (the number of emerged seedlings that survived divided by total the number of emerged seedlings $\times 100 \%)$ were noted $(22 \mathrm{~d}$ after seeding). Shoot height, hypocotyl height, and shoot width were measured biweekly until the termination of the experiment $(18,32$, and $49 \mathrm{~d}$ after seeding). Shoot height was the distance from the substrate surface to the top of the shoot; shoot width was the maximum horizontal distance between two leaf tips. At harvest (49 d after seeding), leaf area was measured with a leaf area meter (LI-3100; LI-COR, Inc., Lincoln, Nebr.). The growing medium was washed off the roots, and the longest root length was measured. Shoot(stems and leaves), inflorescence, and root tissues were dried in an oven at $80{ }^{\circ} \mathrm{C}$ for at least 3 d; then dry weights were measured. Compactness [shoot (not including inflorescence) dry weight/height], and specific leaf weight (leaf dry weight/leaf area) were calculated from these data. Specific leaf weight is also referred to as leaf mass per unit area. Compactness is a quantitative estimate of plant fullness; a plant with a larger compactness ratio would appear fuller. For example, a plant that weighs 300 $\mathrm{g}$ and is $0.1 \mathrm{~m}$ tall would have a compactness ratio of 3000 . A plant that weighs $600 \mathrm{~g}$ and is $0.1 \mathrm{~m}$ tall would have a compactness ratio of 6000 and appear fuller. All living seedlings except those from the border were harvested for shoot data, but for roots, only four representative plants were harvested.

Leaf water relations. Midday leaf $\Psi_{\mathrm{w},} \Psi_{\mathrm{p}}$, and $\Psi$ of marigold cotyledons at $18 \mathrm{~d}$ after seeding and second acropetal leaves at 32 and $49 \mathrm{~d}$ after seeding were measured using thermocouple psychrometers (leaf cutter psychrometers; J.R.D. Merrill Specialty Equipment, Logan, Utah). Plants from three representative blocks were selected for psychrometer measurements. Leaf samples enclosed in the psychrometer chambers were equilibrated in a water bath at $25^{\circ} \mathrm{C}$ for $4 \mathrm{~h}$ before measurement. Water potential of intact leaves was measured first using a microvoltmeter. Then, leaf samples were frozen to disrupt cell membranes and remove $\Psi_{p}$. Samples were then re-equilibrated as described above and $\Psi_{\mathrm{s}}$ was measured. $\Psi$ was calculated by subtracting $\Psi_{\mathrm{s}}$ from $\Psi_{\text {w }}$.

Whole plant carbon exchange. In addition to morphological measurements, whole-plant photosynthesis of four blocks was measured at the termination of the experiment. Since few plants were alive in the growing medium containing PEG at $83 \mathrm{~g} \cdot \mathrm{L}^{-1}$ growing medium, photosynthesis and respiration of this treatment were not measured. All plants and growing medium from the outermost rows and dead plants were removed before carbon exchange measurements.

Whole-plant (net) carbon exchange rates were measured in the light (net photosynthesis, $P P F=240 \mu \mathrm{mol} \cdot \mathrm{m}^{-2} \cdot \mathrm{s}^{-1}$ ) and dark (dark respiration). Carbon exchange was measured at 20 min intervals in multiple acrylic chambers as described by van Iersel and Bugbee (2000). Ambient airflow into the system was measured using mass flow meters (GFM37-32; Aalborg Instruments and Controls, Monsey, N.Y.).
Carbon dioxide concentration was measured before and after ambient air entered the chambers using an infrared $\mathrm{CO}_{2}$ analyzer (LI-6262; LI-COR) in differential mode. Respiration was measured outside of growth chambers in acrylic chambers covered with opaque cloths $\left(P P F=0 \mu \mathrm{mol} \cdot \mathrm{m}^{-2} \cdot \mathrm{s}^{-1}\right)$. Each group of plants was measured at $22^{\circ} \mathrm{C}$ until net photosynthesis or respiration rates had stabilized. Any data collected before rates had stabilized were excluded from the analysis. Plants were harvested as described above immediately after net photosynthesis and respiration measurements had ceased. To correct for differences in plant size among treatments, net photosynthesis was divided by leaf area and respiration was corrected for total plant dry weight to determine the specific respiration rate.

Post-transplant morphology. When the seedlings were harvested, six representative plants from outermost rows were transplanted into a six-cell pack (cell volume $=380 \mathrm{~mL}$ ) containing a peat-based growing medium (Fafard 3M; Fafard, Anderson, S.C.). Plants from the outermost rows were selected since all other plants were destructively harvested after photosynthesis measurements. Plants were grown on ebb and flow benches irrigated daily with a $20 \mathrm{~N}-8.7 \mathrm{P}-16.6 \mathrm{~K}$ fertilizer $(20-20-20$ General Purpose, Scotts Company) solution with a $\mathrm{N}$ concentration of $150 \mathrm{mg} \cdot \mathrm{L}^{-1}$. After transplanting, no effort was made to keep the PEG-8000 from leaching out of the growing medium. Height was measured $14 \mathrm{~d}$ after transplanting, and the number of days to the appearance of the first flower (the first basipetal ray flower was bright orange and perpendicular to the peduncle) was noted.

Experimental design and data analysis. The experimental design was a randomized complete block design with 6 replications/ treatment, 16 subsamples/treatment before seedling harvest, and 6 subsamples/treatment after transplanting. For root harvest data, there were 4 subsamples/treatment. Data were analyzed using regression analysis to test for significant $(P<0.05)$ linear and quadratic effects of PEG-8000 concentrations (Proc GLM, Statistical Analysis Systems, Cary, N.C.). Volumetric water contents were averaged over all measurements throughout the experiment for each experimental unit before analysis. All data, excluding growing medium $\Psi_{w}$ and water content, days to emergence, emergence percentage, and percentage survival were analyzed without the highest three treatments due to the high mortality in those three treatments. Leaf water relations data were also further analyzed by testing for correlations between $\Psi_{w}, \Psi_{s}$, and $\Psi_{\mathrm{p}}$ and the seedling height when leaf water relations were measured.

\section{Results and Discussion}

Growing medium $\Psi$ decreased significantly with increasing PEG-8000 concentration in the growing medium (Fig. 1). This was expected, since PEG- 8000 reduces the matric potential of media (Steuter et al., 1981). The growing media containing 70 and $83 \mathrm{~g} \cdot \mathrm{L}^{-1}$ of PEG-8000 had a $\Psi_{w}$ near or below the per- 


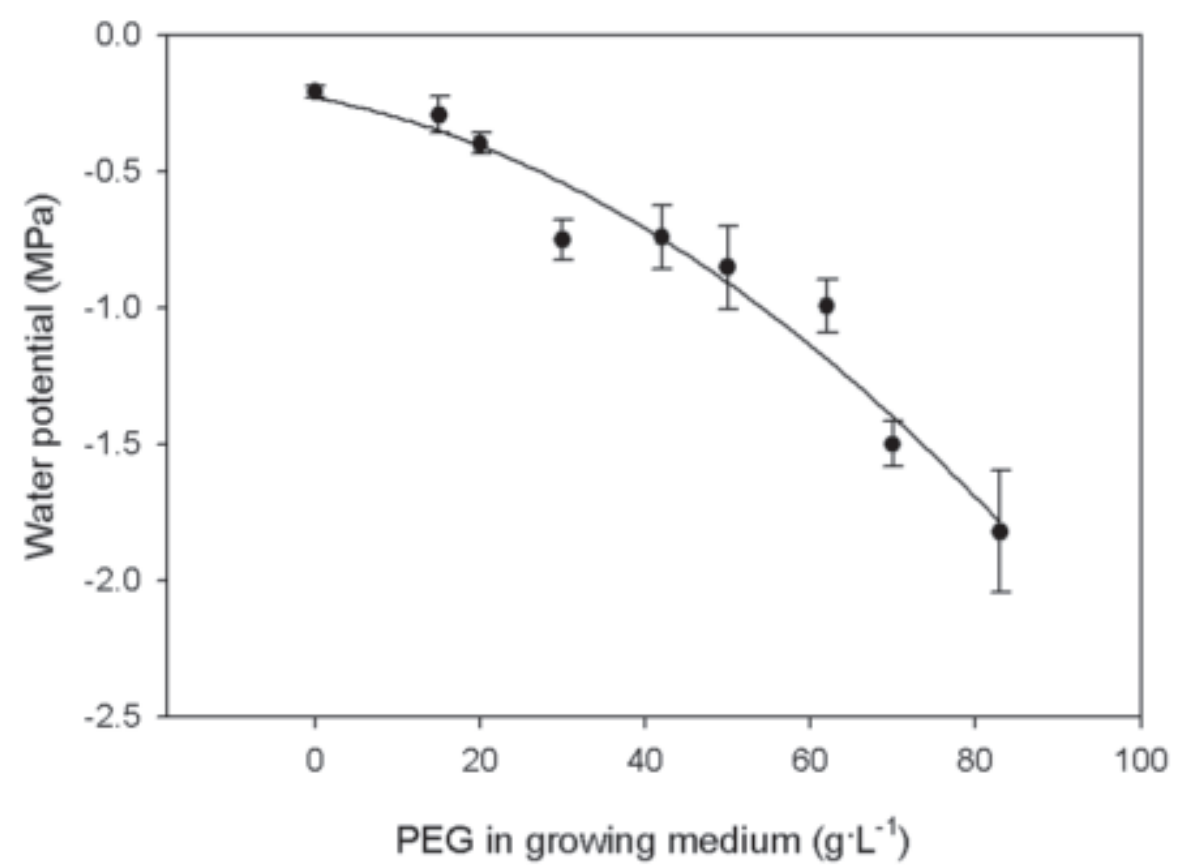

Fig. 1. Water potential of the growing medium at $29.3 \%$ volumetric water content after incorporation of different PEG- 8000 concentrations. Data points are the mean of three measurements, with bars representing the standard error. Regression curve indicates a significant quadratic trend. Water potential $=$ $-0.229-5.67 \times 10^{-3} \times[\mathrm{PEG}]-1.58 \mathrm{H} 10^{-4} \times[\mathrm{PEG}]^{2}, R^{2}=0.71, P=0.0001$.

manent wilting point (-1.5 MPa) (Fig. 1). For remaining treatments, the range of substrate $\Psi_{\text {w }}$ was -0.21 to $-1.00 \mathrm{MPa}$.

The average volumetric water content of the growing media throughout the experiment increased quadratically with increasing PEG concentrations $\left(R^{2}=0.82, P=0.0001\right.$, results not shown), but was similar for growing media treated with 0 to $42 \mathrm{~g} \cdot \mathrm{L}^{-1}$ of PEG- 8000 (volumetric water content $=27 \%$ to $28 \%$ ). However, the daily fluctuations in volumetric water content within each treatment were generally greater than the differences in volumetric water content among treatments within the range of 0 to $50 \mathrm{~g} \cdot \mathrm{L}^{-1}$ of PEG- 8000 . Since the $\Psi_{w}$ of the growing media was measured at a constant (not fluctuating) volumetric water content, the $\Psi_{w}$ in Fig. 1 may not have been entirely representative of substrate $\Psi_{w}$ values throughout the experiment. Volumetric water contents were higher in growing media with PEG concentrations. Thus, the actual $\Psi_{w}$ of growing media throughout the greenhouse was probably higher than the values measured using the vapor pressure osmometer in the lab. For this reason, actual differences in substrate $\Psi_{w}$ among treatments may have been smaller than those shown in Fig. 1.

Drought may reduce seedling emergence and plant establishment (Mohr and Schopfer, 1995). In this experiment, PEG-treated marigold seedlings emerged up to $5 \mathrm{~d}$ later and at lower percentages than nontreated controls (Fig. 2A and B). Seedlings treated with $\geq 60$ $\mathrm{g} \cdot \mathrm{L}^{-1}$ of PEG- 8000 had the lowest emergence percentages $(80 \%$ to $90 \%$, Fig. $2 \mathrm{~B})$. It was surprising that marigolds emerged at such high percentages in growing media with a $\Psi_{\mathrm{w}}$ near the permanent wilting point. However, Colophospermum mopane (Benth.) J. Léonard seedlings imbibed for $24 \mathrm{~h}$ in $\mathrm{CaCl}_{2}$ solutions at $-0.03 \mathrm{MPa}$ grew in PEG solutions in a vermiculite substrate with a $\Psi_{\mathrm{w}}$ as low as -2.1 $\mathrm{MPa}$ (Johnson et al., 1996). Seeds treated with $\leq 50 \mathrm{~g} \cdot \mathrm{L}^{-1}$ of PEG- 8000 emerged at percentages above $90 \%$ and seedling emergence was not delayed $>2$ d compared to control seedlings (Fig. 2A and B).

After emergence, marigold seedlings were transferred from the growth chamber to the greenhouse. Nearly $100 \%$ of marigolds treated with 0 to $30 \mathrm{~g} \cdot \mathrm{L}^{-1}$ of PEG and $80-90 \%$ of seedlings treated with 42 to $50 \mathrm{~g} \cdot \mathrm{L}^{-1}$ of PEG- 8000 survived (Fig. 2C). However, about $40 \%$ to $60 \%$ of emerged seedlings treated with 60 to $83 \mathrm{~g} \cdot \mathrm{L}^{-1}$ of PEG-8000 died after exposure to the higher light levels and variable temperature and relative humidity typical in greenhouses. In commercial seedling production, growers aim for nearly $100 \%$ emergence and establishment (Corr, 1998). If 60 to $83 \mathrm{~g} \cdot \mathrm{L}^{-1}$ of PEG-8000 is used, empty cells would have to be replugged with living seedlings, at a significant cost to plug growers. Treatments with emergence or survival percentages below $80 \%$ were considered unacceptable for practical applications; those treatments ( 60 to $83 \mathrm{~g} \cdot \mathrm{L}^{-1}$ of PEG- 8000 ) will not be discussed further.

Throughout the experiment, seedlings treated with increasing PEG-8000 rates in the growing medium were shorter and more narrow (Fig. 3A-F). At 18, 32, and $49 \mathrm{~d}$ after seeding, marigolds treated with $50 \mathrm{~g} \cdot \mathrm{L}^{-1}$ of PEG- 8000 were $33 \%, 38 \%$, and $38 \%$ shorter, respectively, than nontreated seedlings (Fig. $3 \mathrm{~A}-\mathrm{C})$. At $18 \mathrm{~d}$ after seeding, hypocotyl height decreased with increasing amounts of PEG8000 (Fig. 3A). The most narrow plants were those treated with $50 \mathrm{~g} \cdot \mathrm{L}^{-1}$ of PEG- 8000 and they were $33 \%, 36 \%$, or $15 \%$ less wide than nontreated seedlings when measured 18, 32, or 49 dafter seeding, respectively (Fig. 3D-F).

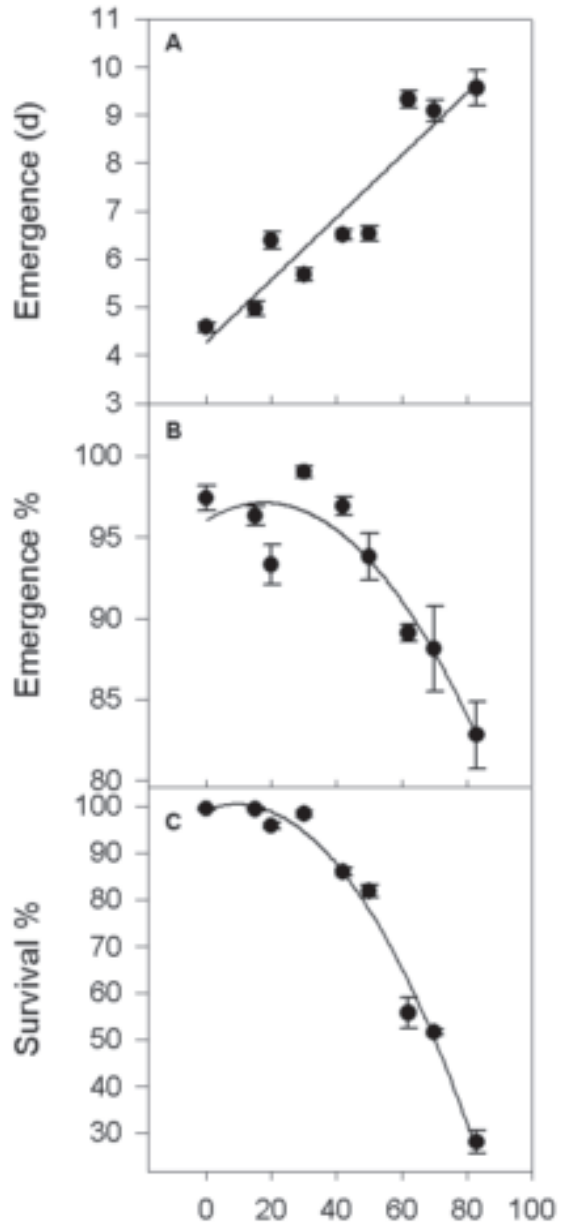

PEG in growing medium $\left(\mathrm{g} \cdot \mathrm{L}^{-1}\right)$

Fig. 2. Effects of PEG-8000 concentration in the growing medium on (A) seedling days to emergence, $(\mathbf{B})$ emergence percentage, and $(\mathbf{C})$ percentage survival of marigold. Data points are the mean of six replications, with bars representing the standard error. Regression curves indicate significant linear or quadratic effects. Days to emergence $=4.3+0.276 \times[$ PEG $], r^{2}$ $=0.76, P=0.0001$; emergence percentage $=$ $96.1+0.116 \times[\mathrm{PEG}]-0.00334 \times[\mathrm{PEG}]^{2}, R^{2}$ $=0.46, P=0.0001$; survival percentage $=99.2$ $+0.259 \times[\mathrm{PEG}]-0.0127 \times[\mathrm{PEG}]^{2}, R^{2}=0.91$, $P=0.0001$.

Similarly, postgermination PEG drenches reduced elongation of marigolds and salvia (Burnett et al., 2005).

Leaf areas and root lengths of PEG-treated marigolds decreased as plants were treated with increasing quantities of PEG-8000 (Fig. $4 \mathrm{~A}$ and $\mathrm{B}$ ). Seedlings treated with $50 \mathrm{~g} \cdot \mathrm{L}^{-1}$ of PEG- 8000 were affected the most and had $43 \%$ smaller leaf areas and 53\% shorter roots than control plants (Fig. 4A and B). Root, shoot, and inflorescence dry weights decreased with increasing PEG-8000 rate. Root, shoot, and inflorescence dry weights of plants treated with $50 \mathrm{~g} \cdot \mathrm{L}^{-1}$ of PEG-8000 were reduced by $57 \%, 79 \%$, and $57 \%$, respectively (Fig. 4C). Roots of drought-stressed plants elongate more slowly than unstressed plants, but drought stress affects roots less than leaves (Jones, 1992; Kramer and Boyer, 1995). In our ex- 


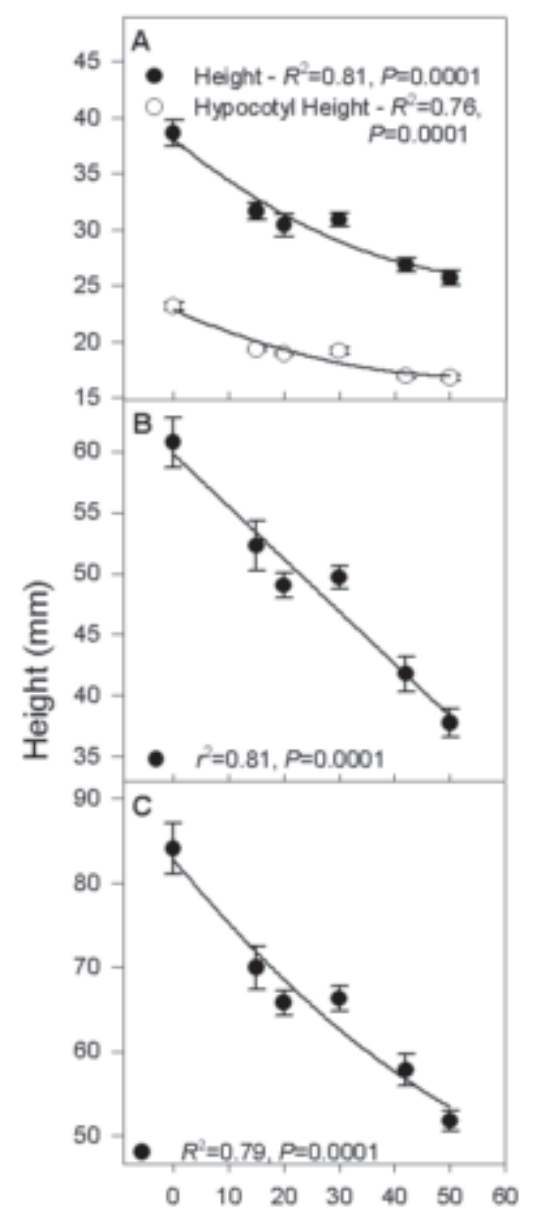

PEG in growing medium $\left(\mathrm{g} \cdot \mathrm{L}^{-1}\right)$

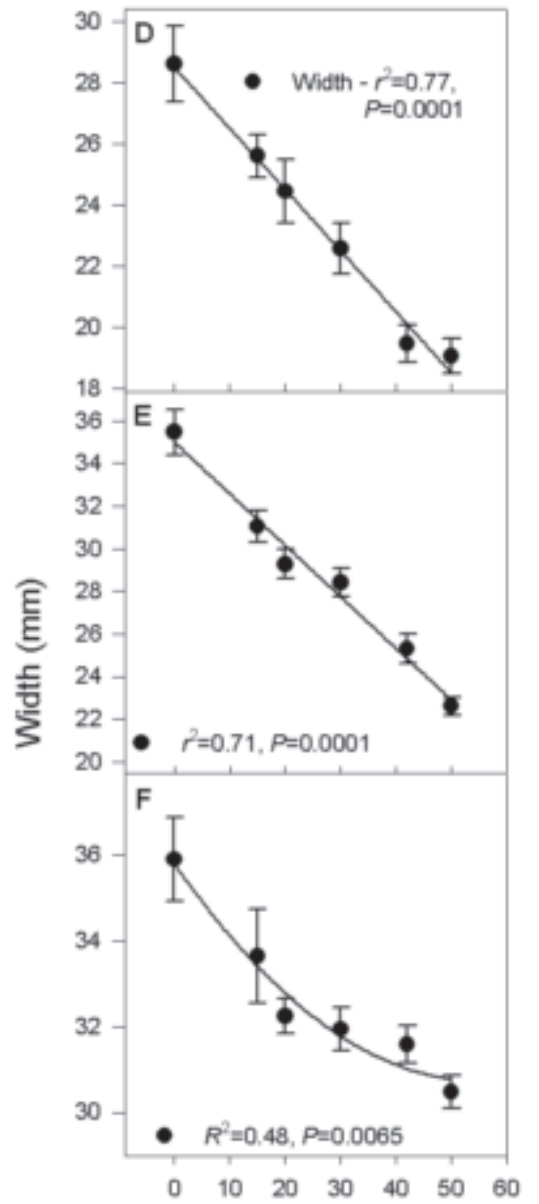

PEG in growing medium $\left(\mathrm{g} \cdot \mathrm{L}^{-1}\right)$

Fig. 3. The influence of different rates of PEG- 8000 in the growing medium on the height and width of marigold seedlings (A and D, for height and width, respectively) 18, (B and $\mathbf{E}$ ) 32, and (C and F) 49 $\mathrm{d}$ after seeding (harvest). Hypocotyl height was measured $18 \mathrm{~d}$ after seeding (A). Data points are the mean of six replications, with bars representing the standard error. Regression curves indicate significant linear or quadratic effects.

periment, PEG affected roots less than shoots. In this experiment, most of the plants treated with $50 \mathrm{~g} \cdot \mathrm{L}^{-1}$ or less of PEG-8000 had roots that extended to the bottom half of cells and appeared healthy and white.

Compactness (dry weight/plant height) was decreased by PEG-8000; PEG-treated seedlings were about $20 \%$ less compact than controls (Fig. 5). Similarly, compactness of hydroponic marigolds treated with PEG-8000 (Burnett, 2004) and drought-stressed marigolds (van Iersel and Nemali, 2004) was lower compared to nonstressed controls. Drought appears to affect compactness in a speciesspecific manner, though, because PEG-treated salvia were more compact than nontreated salvia (Burnett et al., 2005). However, height, and particularly hypocotyl height, is a more important indicators of marigold seedling quality than compactness. Tall, compact seedlings would be more expensive to ship than short, less compact seedlings.

Leaf water relations. Eighteen days after seeding, leaf $\Psi_{w}, \Psi_{s}$, and $\Psi_{\mathrm{p}}$ decreased with increasing PEG-8000 (Fig. 6A). Plants grown with 20 to $50 \mathrm{~g} \cdot \mathrm{L}^{-1}$ of PEG- 8000 had a $\Psi_{\mathrm{p}}$ close to 0 , compared to controls which had an average $\Psi_{\mathrm{p}}$ of $0.28 \mathrm{MPa}$. Although PEG-treated plants had low $\Psi_{\mathrm{p}}$, they were not wilted. Reductions in $\Psi_{w}$, and especially in $\Psi_{\mathrm{p}}$, are associated with decreased cell elongation (Cosgrove, 1997). Eighteen d after seeding, seedling height was positively correlated with $\Psi_{\mathrm{w}}$ and $\Psi_{\mathrm{s}}\left(\Psi_{\mathrm{w}} r^{2}=\right.$ $\left.0.48, P=0.0304 ; \Psi_{\mathrm{s}}, r^{2}=0.46, P \stackrel{\mathrm{w}}{=} 0.0394\right)$. So, it appears that PEG-8000-induced changes in leaf water relations were important for observed reductions in plant growth.

Leaf $\Psi_{w}$ also decreased with increasing PEG-8000 concentration 32 and $49 \mathrm{~d}$ after seeding (Fig. 6B and C). At $32 \mathrm{~d}$ after seeding, $\Psi_{\text {was }}-0.75$ and $-1.65 \mathrm{MPa}$ for controls and PËG treatments $\left(50 \mathrm{~g} \cdot \mathrm{L}^{-1}\right)$, respectively. Leaf $\Psi_{\mathrm{s}}$ decreased with increasing PEG-8000 rate 32 and $49 \mathrm{~d}$ after seeding (Fig. 6B and C). Turgor potential was not affected on either of the last two measurement dates, and was positive for all PEG concentrations. Seedling height at $32 \mathrm{~d}$ after seeding was significantly lower in seedlings with decreasing $\Psi_{\mathrm{w}}\left(r^{2}=0.62, P=\right.$ $0.0029)$. At $49 \mathrm{~d}$ after seeding, $\Psi_{\mathrm{s}}$ and $\Psi_{\mathrm{w}}$ were correlated with seedling height $\left(\Psi_{\mathrm{w}}, r^{2}=0.37\right.$, $P=0.02 ; \Psi_{\mathrm{s}}, r^{2}=0.71, P=0.0005$ ).

PEG affected leaf $\Psi_{\mathrm{w}}$ and $\Psi_{\mathrm{p}}$ less as the experiment progressed. There are several possible explanations for this observed trend. Ishida (1991) reported that PEG is adsorbed

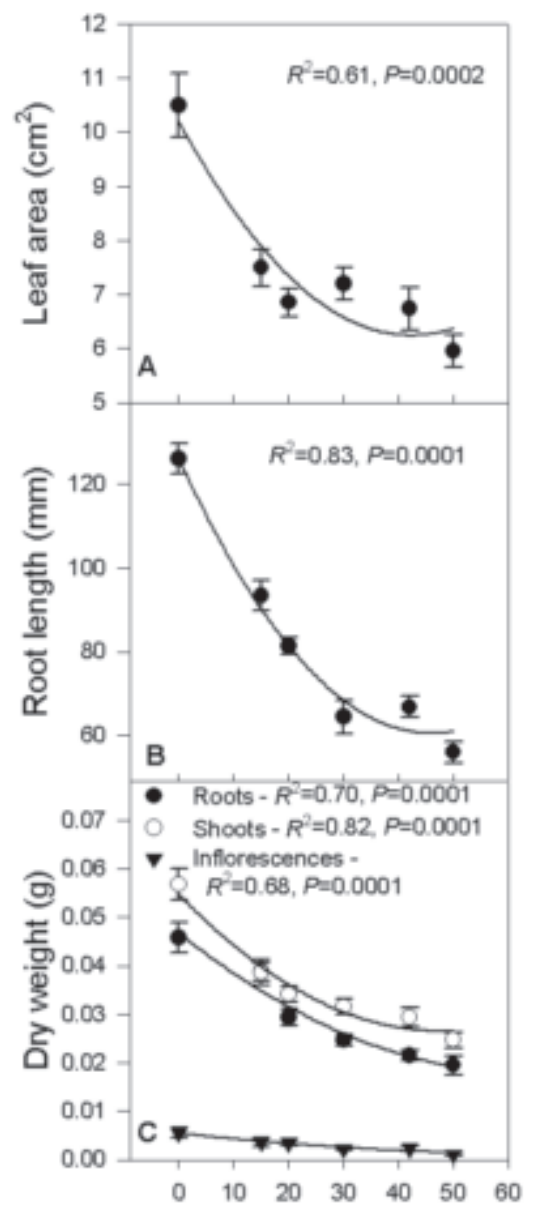

PEG in growing medium $\left(\mathrm{gL}^{-1}\right)$

Fig. 4. The effects of PEG- 8000 in the growing medium on the (A) leaf area, (B) longest root length, and (C) shoot, root, and inflorescence dry weight of marigold per plant at harvest (49 $\mathrm{d}$ after seeding). Data points are the mean of six replications, with bars representing the standard error. Regression curves indicate significant quadratic effects.

to dry soils. However, PEG is highly water soluble and easily leaches out of substrates. Although we attempted to prevent leaching, we cannot rule out the possibility that some PEG may have leached out of the growing medium. It is also possible that marigolds acclimated to the low growing medium $\Psi_{\mathrm{w}}$ via osmotic adjustment (Kramer and Boyer, 1995). PEG-treated marigolds had lower leaf $\Psi_{\mathrm{s}}$ than nontreated marigolds throughout the experiment. Finally, it is also possible that soil microbes degraded some of the PEG- 8000 in the growing medium since Haines and Alexander (1975) reported that PEG with a molecular weight up to 20,000 was degraded by soil microbes. It is unknown whether the microorganisms capable of degrading PEG were present in our growing medium.

Whole-plant carbon exchange. Net photosynthesis decreased with increasing PEG8000 concentration in the growing medium on both a whole plant (Fig. 7A) and unit leaf area bases (Fig. 7C). Plants commonly reduce photosynthesis in response to drought. For example, rosemary (Rosmarinus officinalis L.) 


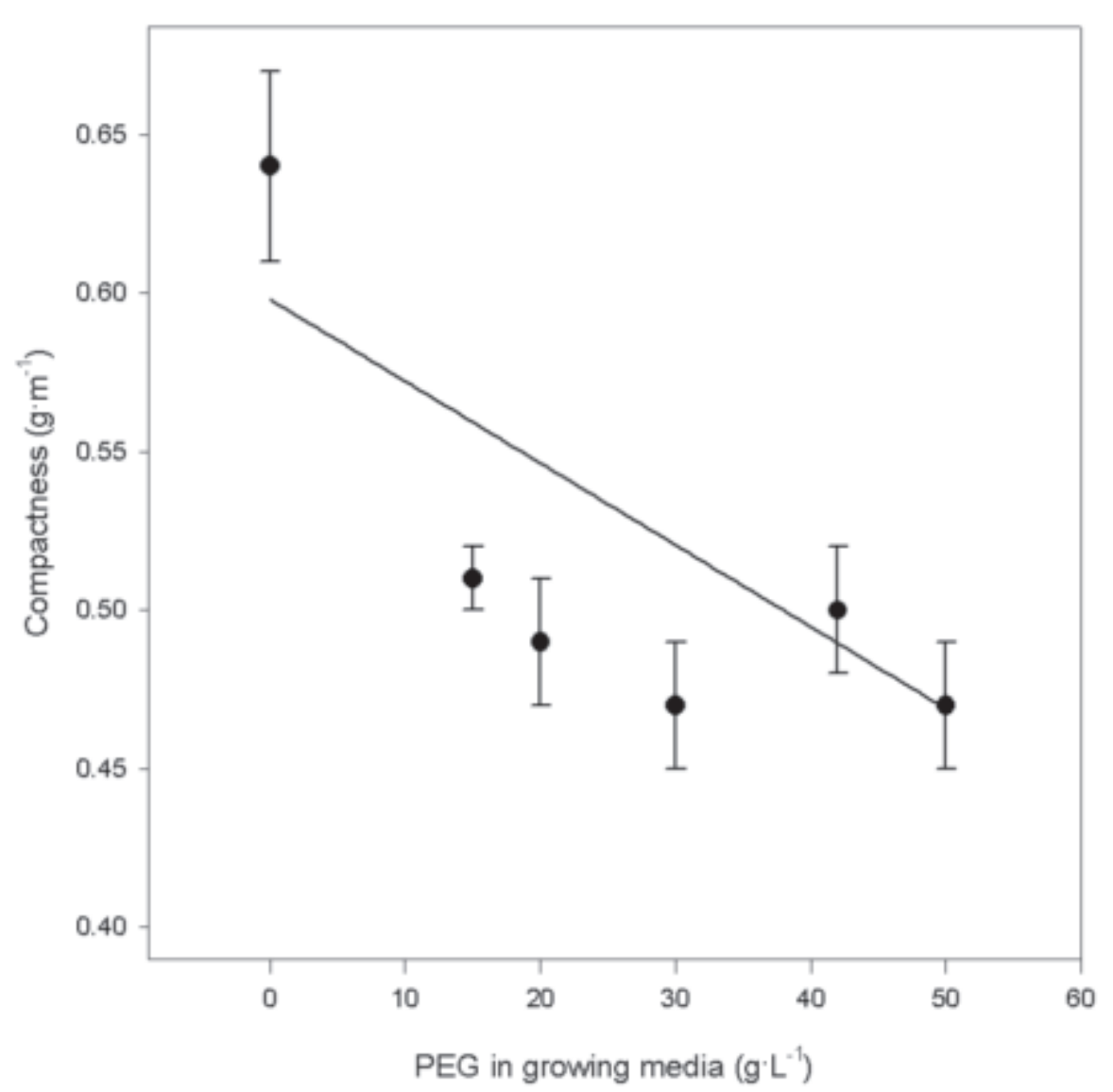

Fig. 5. The influence of different rates of PEG-8000 in the growing medium on compactness (shoot dry weight/height) of marigold per plant at harvest ( $49 \mathrm{~d}$ after seeding). Data points are the mean of six replications, with bars representing the standard error. Regression curves indicate significant linear effects. Compactness $=0.598-0.00285 \times[\mathrm{PEG}], r^{2}=0.69, P=0.0001$.

and lavender (Lavendula stoechas L.) grown without water for ten d (leaf $\Psi_{\mathrm{w}}=-3.0 \mathrm{MPa}$ ) decreased both whole-plant photosynthesis and photosynthesis per unit leaf area (Nogués et al., 2001).

Leaf photosynthesis is reduced during drought by reductions in stomatal or mesophyll conductance, Rubisco activity, or electron transport and phosphorylation within the chloroplast (Jones, 1992; Kaiser, 1987). Reduced net photosynthesis was probably caused by low substrate $\Psi_{w}$, which decreased leaf $\Psi_{\mathrm{w}}$ (statistically significant at 18 and $32 \mathrm{~d}$ after seeding, Fig. 6), which in turn may cause a reduction in stomatal conductance (Jones, 1992). Conversely, anatomical adaptation or leaf damage can reduce mesophyll conductance. In this experiment, it was not possible to measure mesophyll or stomatal conductance because the leaves were prohibitively small. Moisture-stress-conditioned annual salvia exposed to subsequent drought reduced stomatal conductance and thus photosynthesis. By comparison, salvias that were not moisture-stress conditioned and then drought-stressed reduced photosynthesis by 10 -fold decreases in mesophyll conductance (Eakes et al., 1991).

Specific leaf weight, a measure of leaf thickness, decreased quadratically with increasing PEG concentration $\left(R^{2}=0.72, P=0.0001\right.$; results not shown). The specific leaf weight for control seedlings was $22 \mathrm{~g} \cdot \mathrm{m}^{-2}$, compared

to a specific leaf weight of $14 \mathrm{~g} \cdot \mathrm{m}^{-2}$ for plants treated with $50 \mathrm{~g} \cdot \mathrm{L}^{-1}$ of PEG-8000. Gonzalezet al. (1995) reported that bean plants (Phaseolus vulgaris L.) with lower specific leaf weights have lower carbon exchange rates than bean plants with higher specific leaf weights. Similarly, leaf apparent photosynthesis of soybean [Glycine max (L.) Merr.] was higher in soybean with high specific leaf weights (and low leaf rugosity) (Thompson et al., 1995). Since nontreated marigolds had higher specific leaf weights, they would also likely have more photosynthesizing tissue per unit leaf area. Reductions in specific leaf weight, in addition to PEG effects on leaf water relations, can explain the decrease in leaf photosynthesis with increasing PEG concentrations.

Lower net photosynthesis rates with increasing PEG-concentrations undoubtedly contributed to reductions in plant growth. Whole-plant net photosynthesis and net photosynthesis per unit leaf area were close to zero for marigolds treated with 42 and 50 $\mathrm{g} \cdot \mathrm{L}^{-1}$ of PEG- 8000 . Photosynthesis normally exceeds respiration in healthy, vigorous plants, however, if respiration exceeds photosynthesis, growth will slow or cease, or plant organs will die (Amthor, 2000; Kramer and Boyer, 1995). Net photosynthesis rates for seedlings treated with 42 and $50 \mathrm{~g} \cdot \mathrm{L}^{-1}$ of PEG-8000 were so low that these treatments would be undesirable.

Whole-plant dark respiration also decreased

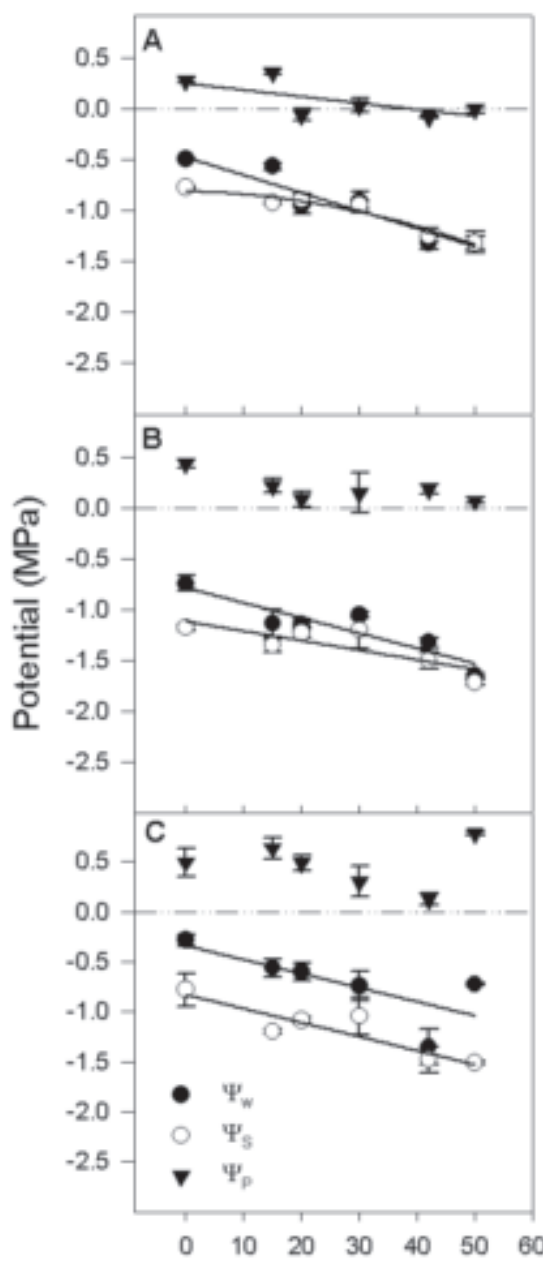

PEG in growing medium $\left(\mathrm{g}^{-1}\right)$
Fig. 6. The influence of different rates of PEG- 8000 in the growing medium on water $\left(\Psi_{w}\right)$, osmotic $(\Psi)$, and turgor potential $\left(\Psi_{\mathrm{p}}\right)$ of marigold leaves $(\mathbf{A})$ 18, (B) 32, and (C) $49 \mathrm{~d}$ after seeding. Measurements were taken midday on whole cotyledons $18 \mathrm{~d}$ after seeding and on leaf tips of the second acropetal leaf 32 and $49 \mathrm{~d}$ after seeding. Data points are the mean of three replications, with bars representing the standard error. Regression curves indicate significant linear or quadratic effects. Eighteen days after seeding, $\Psi_{w}=-0.473$ $-0.0176 \times[\mathrm{PEG}], r^{2}=0.69, P=0.0004 ; \Psi=$ $-0.812-1.02 \times 10^{-3} \times[\mathrm{PEG}]-1.88 \times 10^{-4} \times\left[\mathrm{PEG}^{\mathrm{s}}\right]^{2}$, $R^{2}=0.66, P=0.0080 ; \Psi=0.248-6.39 \times 10^{-3} \times$ [PEG], $r^{2}=0.46, P=0.0324 ; 32 \mathrm{~d}$ after seeding, $\Psi_{\mathrm{w}}=-0.787-0.0149 \times[\mathrm{PEG}], r^{2}=0.60, P=$ $0.0006 ; \Psi=-1.12-0.0094 \times[\mathrm{PEG}], r^{2}=0.30, P$ $=0.0443 ; 49 \mathrm{~d}$ after seeding, $\Psi=-0.34-0.014 \times$ $[\mathrm{PEG}], r^{2}=0.35, P=0.0257 ; \Psi^{\mathrm{w}}=-0.83-0.014$ $\times[\mathrm{PEG}], r^{2}=0.63, P=0.0026^{\mathrm{s}}$.

with increasing PEG-8000 rate (Fig. 7B). However, when respiration was corrected for dry weight, specific respiration rose with increasing PEG concentration (Fig. 7D). Although stomata typically close when soil $\Psi$ is low, this does not affect respiration as much available in the atmosphere and can enter the leaf in sufficient quantities through diffusion (Kramer and Boyer, 1995). Whole-plant respiration actually exceeded net photosynthesis in as photosynthesis because oxygen is readily 


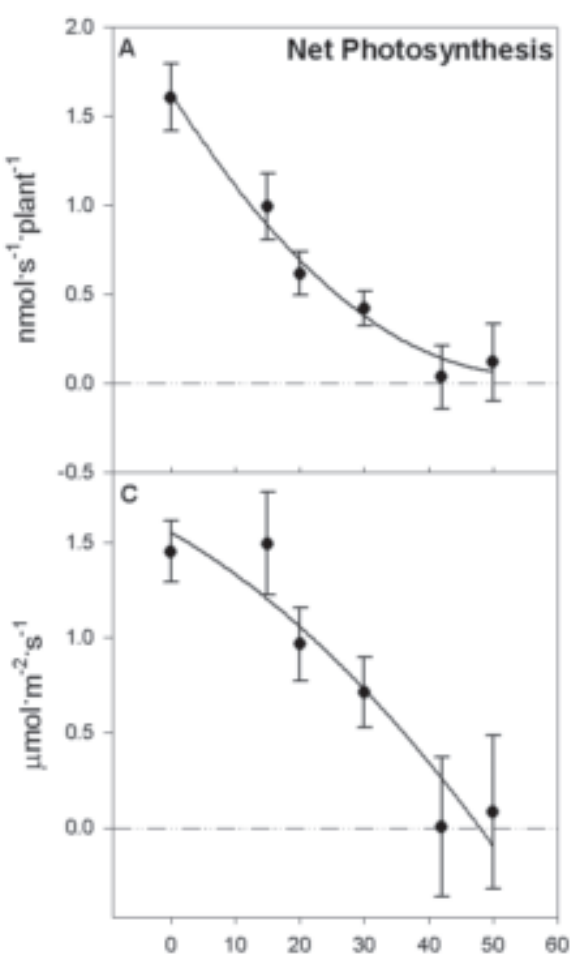

PEG in growing medium $\left(g \cdot \mathrm{L}^{-1}\right)$
Fig. 7. The influence of different rates of PEG-8000 in the growing medium on photosynthesis (A and $\mathbf{C})$ and dark respiration (B and $\mathbf{D}$ ) of marigold plants $49 \mathrm{~d}$ after seeding. Photosynthesis and respiration are shown on a whole plant basis (upper panels) and are corrected for leaf area (photosynthesis) or total plant dry weight (respiration) in the lower panels. Data points are the mean of four replications, with bars representing the standard error. Regression curves indicate significant linear or quadratic effects. Photosynthesis $=1.62-5.73 \times 10^{-2} \times[\mathrm{PEG}]+5.28 \times 10^{-4} \times[\mathrm{PEG}]^{2}, R^{2}=0.62, P=0.0021$ photosynthesis $/$ leaf area $=1.55-1.93 \times 10^{-2} \times[\mathrm{PEG}]-2.72 \mathrm{H} 10^{-4} \times[\mathrm{PEG}]^{2}, R^{2}=0.49, P=0.0242$; respiration $=1.26-7.47 \times 10^{-3} \times[\mathrm{PEG}], r^{2}=0.65, P=0.0004 ;$ respiration/dry weight $=12.2+0.246$ $\times[\mathrm{PEG}], r^{2}=0.73, P=0.0001$.

plants grown with PEG concentrations from 42 to $50 \mathrm{~g} \cdot \mathrm{L}^{-1}$. This could have been due partly to respiration by substrate microbes, which may affect photosynthesis and respiration measurements substantially when small seedlings are measured (van Iersel and Bugbee, 2000).

Similarly, drought-stressed rosemary and lavender had lower whole shoot respiration than nonstressed plants (Nogués et al., 2001). Respiration per unit dry matter was not reported in their experiment. McCree (1986) reported that stressed plants may decrease or increase whole plant respiration compared to nonstressed plants. Growth respiration usually decreases while maintenance respiration usually increases under drought (McCree, 1986). In this case, the increase in specific respiration with increasing PEG concentrations also may have been due to differences in plant size, since larger plants often have lower specific respiration rates (van Iersel, 2003).

Post-transplant morphology. After transplanting, the time to flowering increased with increasing amounts of PEG-8000 in the growing medium $\left(r^{2}=0.74, P=0.0001\right)$. Plants grown with 42 or $50 \mathrm{~g} \cdot \mathrm{L}^{-1}$ of PEG-8000 flowered about $5 \mathrm{~d}$ after nontreated plants. Germination delays may have caused at least part of the flowering delay. PEG-treated marigolds germinated up to two $\mathrm{d}$ and flowered up to five $\mathrm{d}$ later than nontreated plants. However, PEG-treated

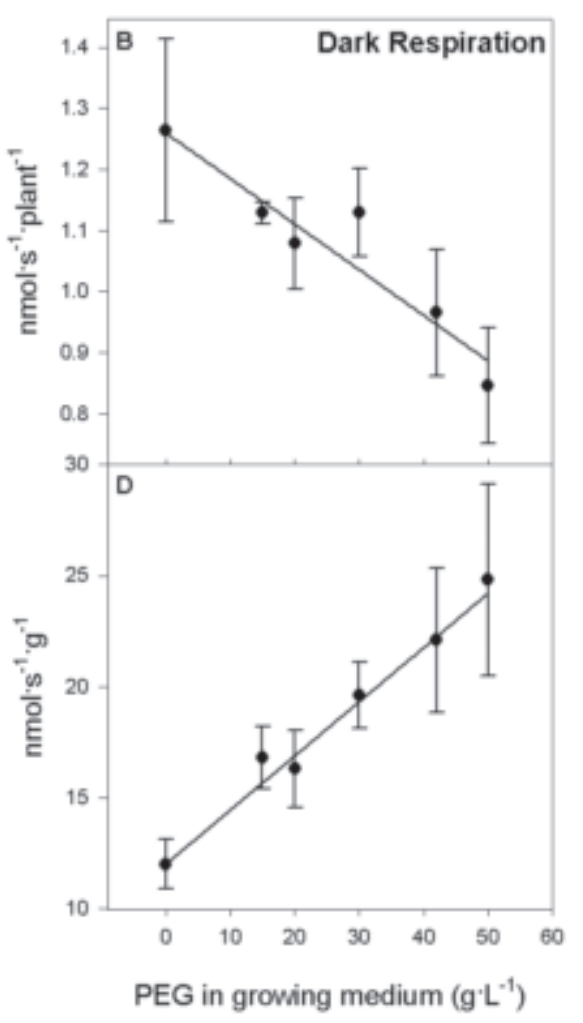

tion regimes. Concentrations above $30 \mathrm{~g} \cdot \mathrm{L}^{-1}$ should be avoided. Rates of 62 to $83 \mathrm{~g} \cdot \mathrm{L}^{-1}$ of PEG-8000 were undesirable because they reduced emergence and survival of seedlings. Whole plant photosynthesis rates of plants treated with 42 to $50 \mathrm{~g} \cdot \mathrm{L}^{-1}$ of PEG were close to zero. These plants were probably growing very little and therefore may also be undesirable for commercial marigold plug growers. Reductions in leaf $\Psi_{w}$ and net photosynthesis contributed to slower growth in PEG-treated marigolds. PEG-treated marigolds remained shorter than nontreated marigolds 2 weeks after transplanting. Future research should focus on improving the commercial applicability of using osmotic compounds, such as PEG-8000, to reduce elongation of seedlings. It is important to develop watering regimes for growing plants under osmotic stress, since PEG-8000 is highly water-soluble and easily leaches out of the growing media.

\section{Literature Cited}

Amthor, J.S. 2000. The McCree-de Wit-Penning de Vries-Thornley respiration paradigms: 30 years later. Ann. Bot. 86:1-20.

Armitage, A.M. 2001. Armitage's manual of annuals, biennials, and half-hardy perennials. Timber Press, Inc. Portland, Ore.

Burnett, S., P. Thomas, and M. van Iersel. 2005. Post-germination drenches with PEG-8000 reduce growth of salvia and marigold. HortScience 40:675-679.

Burnett, S.E. 2004. Effects of polyethylene glycol on the morphology of ornamental seedlings. PhD diss. Univ. Ga., Athens.

Corr, B. 1998. Impatiens (bedding plant), p. 567-575. In: V. Ball (ed.). Ball redbook. 16th ed. Ball Publ., Batavia, Ill.

Cosgrove, D.J. 1997. Relaxation in a high-stress environment: the molecular bases of extensible cell walls and cell enlargement. Plant Cell 9:1031-1041

Eakes, D.J., R.D. Wright, and J.R. Seiler. 1991. Moisture stress conditioning effects on Salvia splendens 'Bonfire'. J. Amer. Soc. Hort. Sci. 116:716-719.

Gonzalez, A., S.E. Beebe, R.E. Macchaivelli, J. Lynch, and J.M. Tohme. 1995. Characters related to leaf photosynthesis in wild populations and landraces of common bean. Crop Sci. 35:1468-1476.

Haines, J.R. and M. Alexander. 1975. Microbial degradation of polyethylene glycols. Appl. Microbiol. 29:621-625.

Ishida, T. 1991. Effect of organic matter and allophane on adsorption of polyethylene glycol onto some soils. Austral. J. Soil Sci. 29:515-525.

Johnson, J.M., J. Pritchard, J. Gorham, and A.D. Tomos. 1996. Growth, water relations and solute accumulation in osmotically stressed seedlings of the tropical tree Colophospermum mopane. Tree Physiol. 16:713-718.

Jones, H.G. 1992. Plants and microclimate: a quantitative approach to environmental plant physiology. 2nd ed. Cambridge Univ. Press, Cambridge, U.K.

PEG-8000 concentrations from 15 to 30 $\mathrm{g} \cdot \mathrm{L}^{-1}$ reduced growth and hypocotyl height of French marigold without negatively affecting germination. Research exploring the use of PEG-8000 in commercial marigold seedling production should use these rates as a starting point for determining how use of PEG could be incorporated into produc-
Kaiser,W.M. 1987. Effects of water deficit on photosynthetic capacity. Physiol. Plant. 71:142-149.

Kessler, Jr., J.R. 1998. Greenhouse production of marigolds. Ala. Coop. Ext. Syst., ANR-1125.

Kjellander, R. and E. Florin. 1981. Water structure and changes in thermal stability of the system poly (ethylene oxide)-water. J. Chem. Soc. Faraday Trans. I. 77:2053-2077.

Kramer, P.J. and J.S. Boyer. 1995. Water relations 
of plants and soils. Academic Press, San Diego, Calif.

Lagerwerff, J.V., G. Ogata, and H.E. Eagle. 1961. Control of osmotic pressure of culture solutions with polyethylene glycol. Science 133:1486-1487.

Latimer, J.G. and R.F. Severson. 1997. Effect of mechanical and moisture-stress conditioning on growth and cuticle composition of broccoli transplants. J. Amer. Soc. Hort. Sci. 122:788-791.

Liptay, A., P. Sikkema, and W. Fonteno. 1998. Transplant growth control through water deficit stress-A review. HortTechnology 8:540-543.

Loomis, R.S. and J.S. Amthor. 1999. Yield potential, plant assimilatory capacity, and metabolic efficiencies. Crop Sci. 39:1584-1596.

McCree, K.J. 1986. Whole-plant carbon balance during osmotic adjustment to drought and salinity stress. Austral. J. Plant Physiol. 13:33-43.

Michel, B.E. 1983. Evaluation of the water potentials of solutions of polyethylene glycol 8000 both in the absence and presence of other solutes. Plant Physiol. 72:66-70.

Mohr, H. and P. Schopfer. 1995. Plant physiology. Springer-Verlag, Berlin, Germany.

Nogués, S., S. Munné-Bosch, J. Casadesús, M. López-Carbonell, and L. Alegre. 2001. Daily time course of whole-shoot gas exchange rates in two drought-exposed Mediterranean shrubs. Tree Physiol. 21:51-58.

Sommer, H.E., C.L. Brown, and H.Y. Wetzstein. 1999. The influence of intermittent soil drying on growth, cell number, and final cell length in the pith of mature internodes in Helianthus annus L. and Liquidambar styraciflua L. Plant Soil 210:51-59.

Steuter, A.A., A. Mozafar, and J.R. Goodin. 1981. Water potential of aqueous polyethylene glycol. Plant Physiol. 67:64-67.

Styer, R.C. and D.S. Koranski. 1997. Plug and transplant production: A grower's guide. Ball Publishing, Batavia, Ill.
Thompson, J.A., L.E. Schweitzer, and R.L. Nelson. 1995. Relationship among specific leaf weight, photosynthetic rate, and seed yield in soybean. Crop Sci. 35:1575-1581.

Uniroyal Chemical.2000. Bonzi: Ornamental growth regulator. Uniroyal Chemical product label.

van Iersel, M.W. 2003. Carbon use efficiency depends on growth respiration, maintenance respiration, and relative growth rate: Acase study with lettuce. Plant Cell Environ 26:1441-1449.

van Iersel, M.W. and B. Bugbee. 2000. A multiple chamber, semicontinuous, crop carbon dioxide exchange system: design, calibration, and data interpretation. J. Amer. Soc. Hort. Sci. 125:86-92.

van Iersel, M.W. and K.S. Nemali. 2004. Drought stress can produce small, but not compact marigolds. HortScience 39:1298-1301.

van Volkenburgh, E. 1999. Leaf expansion-An integrating plant behavior. Plant Cell Environ. 22:1463-1473. 